\title{
Epidemiology of Cyclospora Species in Humans in Malatya Province in Turkey
}

\author{
Ulku Karaman $^{1}$; Nilgun Daldal $^{2}$; Ali Ozer $^{3}$; Ozgur Enginyurt ${ }^{4, *}$; Omer Erturk ${ }^{5}$ \\ ${ }^{1}$ Department of Medical Parasitology, Faculty of Medicine, Ordu University, Ordu, Turkey \\ ${ }_{3}^{2}$ Department of Medical Parasitology, Faculty of Medicine, Inonu University, Malatya, Turkey \\ 3 Public Health Department, Faculty of Medicine, Inonu University, Malatya, Turkey \\ ${ }^{4}$ Public Health Department of Family Medicine, Faculty of Medicine, Ordu University, Ordu, Turkey \\ 5 Department of Family Medicine, Faculty of Medicine, Ordu University, Or
${ }_{\text {Literature Department, Faculty of Science, Ordu University, Ordu, Turkey }}$ \\ *Corresponding author: Ozgur Enginyurt,Department of Family Medicine, Faculty of Medicine, Ordu University, Ordu, Turkey. E-mail: enginyurt72@gmail.com
}

Received: March 2, 2014; Revised: May 10, 2014; Accepted: May 31, 2014

\begin{abstract}
Background: Cyclospora species are rare among other Coccidia parasites and can cause recurrent gastroenteritis. Cyclospora spp. can infect reptiles, insects, rodents, and mammals.

Objectives:The present studyaimed to determine the epidemiology of Cyclospora spp. in Malatya province and its neighboring provinces. Patients and Methods: Totally, 2281 stool samples taken from patients with digestive system complaints who referred to the polyclinics affiliated with Inonu University, Faculty of Medicine in Malatya Province and its neighboring provinces, in 2006, and whose stool specimens were submitted to the parasitology department were examined. A questionnaire was developed to determine the epidemiology of Cyclospora spp. in the patients as the dependent variable of the study. All the participants signed an informed written consent. The samples were coated with Entellan ${ }^{\mathrm{TM}}$ after staining via acid-fast staining and were examined on an immersion microscope objective. The data are presented as mean, standard deviation, or number/percentage. The chi-square test was used for the statistical analyses. Statistically, a P value $<0.05$ was accepted as meaningful.

Results: The stool samples were examined via direct microscopic examination and acid-fast staining. Positivity was determined in 129 (5.7\%) cases. In the overall assessment of the patients with respect to general body itching, rectal itching, allergy, immunosuppression plus cancer, shortness of breath, ulcerative colitis, diarrhea, abdominal pain, salivation, constipation, nausea, vomiting, growth retardation, and anemia, there was no significant relationship. However, in the statistical evaluations among the positive cases, the difference was found to be significant.

Conclusions: The study was conducted in Malatya Province, but patients from the neighboring provinces were also included in the evaluation during the study. Of all the positive cases, 5.6\% were those from Malatya Province and its surrounding areas. Additionally, Cyclospora spp. were observed among the patients referring to the polyclinics with digestive system complaints in $8.1 \%$ of those from the Adiyaman province and in $6.9 \%$ of those from the Kahramanmaraş region. The incidence of Cyclospora cayetanensis may be higher in these regions if an epidemiological study is performed. Consequently, we suggest that Cyclospora spp. be investigated in digestive system disorders, especially in immunosuppressed patients.
\end{abstract}

Keywords: Cyclospora; Digestive System; Epidemiology

\section{Background}

Cyclospora species are protozoa from the subclass of Coccidia parasites from Apicomplexa and cause recurrent watery diarrhea, abdominal pain, gas, nausea, vomiting, and non-specific gastrointestinal symptoms (1-3). The oocysts of Cyclospora cayetanensis are approximately $10 \mu \mathrm{m}$, round, and acid-fast stained and when they are excreted in feces, the sporozoites inside them are not developed (4). In the external environment, there are two sporocystsin each oocyst that contain two sporozoites. For the contaminant oocysts to become infective, sporulation is required in the external environment, which affects the epidemiology of this parasite. Therefore, human-to-human transmission via direct contact with feces is very rare. Fresh oocysts recently thrown in the water or food do not cause illness. Not only is it difficult to identify unsporulated Cyclospora oocysts but also they can be easily missed even in patients with impaired immunity because of a very small amount of excretion. Therefore, to facilitate diagnosis, feces samples must be concentrated (5).

Due to the autofluorescence feature of Cyclospora oocysts, the examination of fresh stool samples in ultraviolet fluorescence microscopy is a useful method. Oocysts have been reported to give green fluorescence in 450 $490 \mathrm{~nm}$ excitation filters (3) and bright, yellow-green fluorescence in $380-420 \mathrm{~nm}$ excitation filters (5). In patients infected with this parasite, nausea, vomiting, anorexia, weight loss, and diarrhea persisting from one to 3 weeks

Copyright (C) 2015, Ahvaz Jundishapur University of Medical Sciences. This is an open-access article distributed under the terms of the Creative Commons Attribution-NonCommercial 4.0 International License (http://creativecommons.org/licenses/by-nc/4.0/) which permits copy and redistribute the material just in noncommercial usages, provided the original work is properly cited. 
have been reported (3). Also in the diagnosis of this parasite, the Kinyoun modified acid-fast method is utilized (2, 3). With this method, oocysts are painted from light pink to dark violet pink in different shades. Nevertheless, in some samples, the parasites which have not been painted can also be found.

Cyclospora spp. were first observed by Eimer in 1870, and the first case reported in humans was from Papua New Guinea in 1979 (1). In Turkey, Cyclospora spp. were first identified in a patient with acquired immune deficiency syndrome (AIDS) in 1998. Since then, although there have been reports of cases from various regions in Turkey, there has been no study to date on the epidemiology of this parasite in this country $(1-4,6,7)$.

\section{Objectives}

To the best of our knowledge, this is the first report of Cyclospora spp. in Malatya province. The present study sought to determine the epidemiology of Cyclospora spp. in Malatya province and its neighboring provinces based on the assumption that Cyclospora spp. may cause digestive system complaints.

\section{Patients and Methods}

The population of this study comprised the patients in Malatya province and its neighboring provinces who referred to the polyclinics of Inonu University Medical Faculty in 2006 with digestive system complaints. Totally, 2281 stool specimens sent to the parasitology department were examined.

\subsection{Data Collection}

In the current study, a questionnaire was developed to determine the epidemiology of Cyclospora spp. among people living in Malatya Province and its neighboring provinces as the dependent variable of the study. Moreover, all the participants were asked to complete and sign a form to certify that they were informed about the study.

\subsection{Questionnaire}

A questionnaire was developed to collect the data that could be associated with the presence of Cyclospora spp. The questionnaire was planned to be used during the process of stool specimen submission.

\subsection{Data and Specimen Collection}

The instruments for data collection were administered to patients with digestive system complaints who referred to Inonu university medical faculty polyclinics, including internal diseases, general surgery, pediatrics, infectious diseases, emergency, and gastroenterology clinics, and whose stool specimens were submitted to the parasitology department between 01.01.2006 and 12.31.2006.
The patients were given special containers for stool specimens and instructed to supply 3 - 4 tablespoons of stool specimen in case of diarrhea or the size of a walnut if there was no diarrhea and to close the cover firmly for return to the parasitology laboratory in no more than one hour. After the instructions were given, the questionnaire was administered. The questions in the form were asked and completed by the researcher. Moreover the diagnostic data were provided by the physician and the patient during the patient's anamnesis. Only complaints concerning Cyclospora spp. were covered in the questionnaire.

It was assumed that the participating patients completed the questionnaire truly and frankly. Moreover, the questionnaire was assumed to have the adequate level of validity and reliability. In the previous studies, Cyclospora oocysts were reported due to their autofluorescence feature since the examination of fresh stool samples in ultraviolet fluorescence microscopy is a useful method. Oocysts have been reported to give green fluorescence in 450 - $490 \mathrm{~nm}$ excitation filters (5). The samples were examined by direct microscopy, acid-fast staining, and saline preparation without waiting. The efficacy of the acidfast staining method has been reported previously (8). Additionally, the positive samples were examined with a fluorescent microscope at 395 to $415 \mathrm{~nm}$.

\subsection{Data Analysis}

The data are presented as mean, standard deviation, or number/percentage. The chi-square test was employed for the statistical analyses. A P value $<0.05$ was considered statistically significant. The statistical package for the social sciences (SPSS) (version 11.5) for Windows was used.

\section{Results}

The fecal specimens of 2281 voluntary individuals residing in Malatya province and its neighboring provinces who due to digestive system complaints referred to Inonu university medical faculty polyclinics, including internal diseases, general surgery, pediatrics, infectious diseases, emergency, and gastroenterology clinics, and whose stool specimens were submitted to the parasitology department between 01.01.2006 and 12.31.2006 were examined. There were 129 (5.7\%) cases positive for Cyclospora spp. infection according to saline preparation (Figure 1), acid-fast staining (Figures 2 and 3), and fluorescence microscopy (Figures 4 and 5 ).

The positive samples were also examined via fluorescence microscopy at 395 to $415 \mathrm{~nm}$ : they gave a yellow, greenish shadow. The mean age of the study population was $24.3 \pm 19.7$ years. Based on the results of the analysis, no significant difference was found regarding the disease variable between the different ages $(P>0.05)$. The distribution of the positive cases by month is depicted in Table 1. 
Karaman U et al.

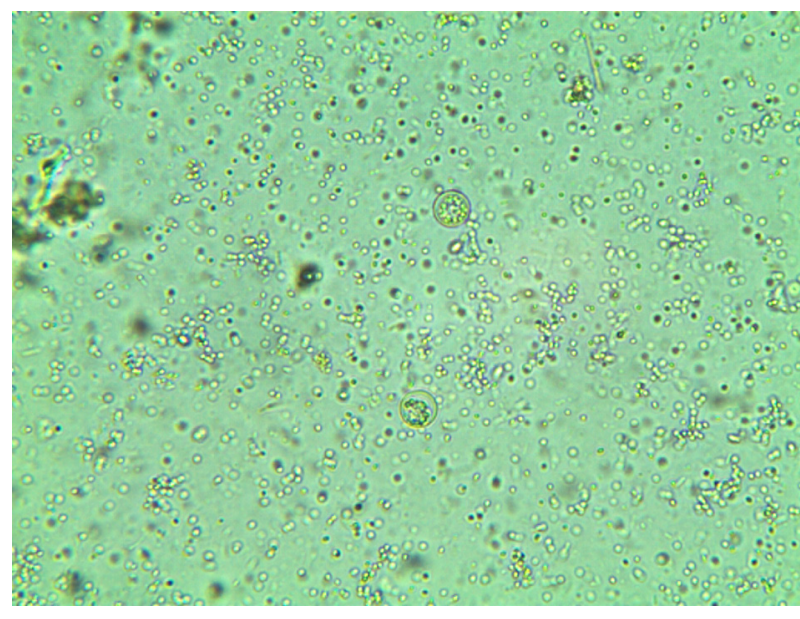

Figure 1. Cyclospora Oocysts Saline Preparation (400 x)

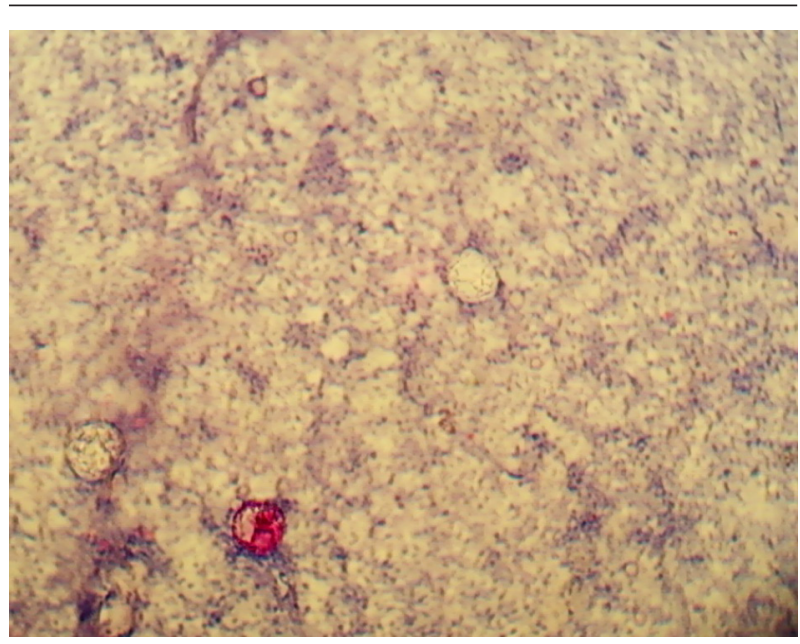

Figure 2. Cyclospora Oocysts Acid-Fast Staining (1000 x)

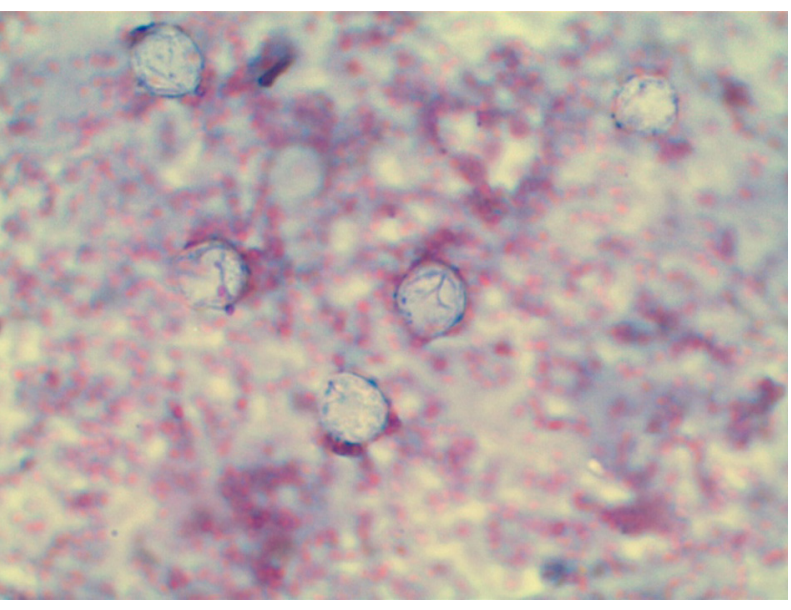

Figure 3. Cyclospora Oocysts Acid-Fast Staining (1000 x)

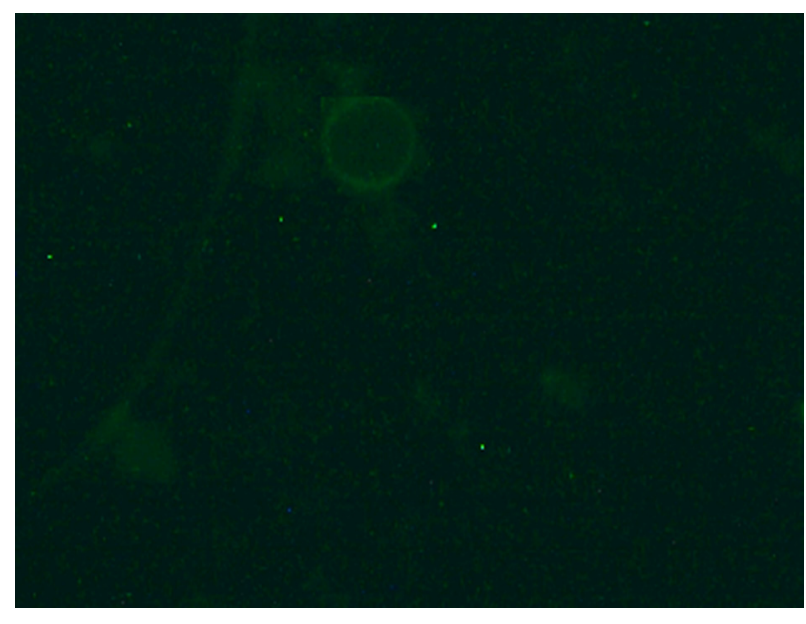

Figure 4. Cyclospora Oocysts Fluorescence Microscopy (400 x)

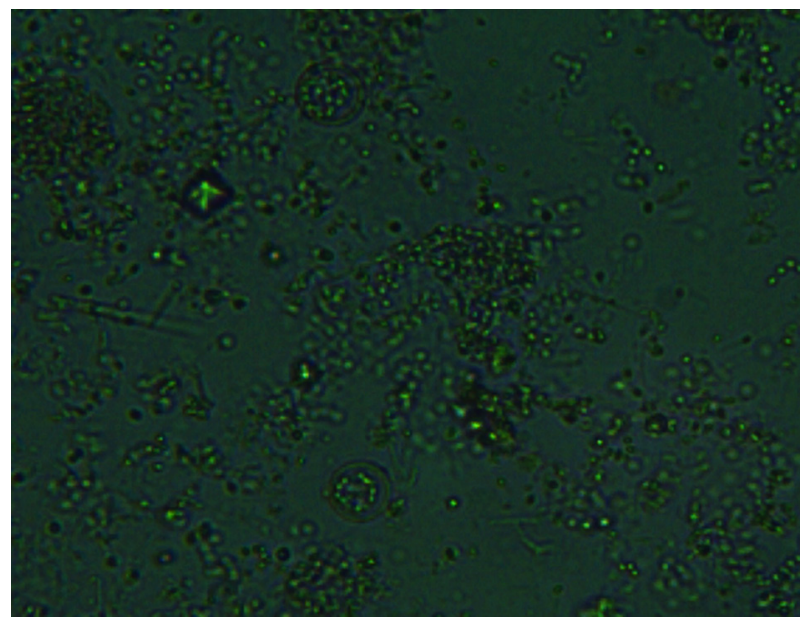

Figure 5. Cyclospora Oocysts Fluorescence Microscopy (400 x)

Table 1. Monthly Distribution of the Samples ${ }^{a}$

\begin{tabular}{lcc}
\hline Months & Negative & Positive \\
\hline January & $1(50.0)$ & $1(50.0)$ \\
\hline February & $89(97.8)$ & $2(2.2)$ \\
\hline March & $323(94.2)$ & $20(5.8)$ \\
\hline April & $350(92.8)$ & $27(7.2)$ \\
\hline May & $306(94.2)$ & $19(5.8)$ \\
June & $348(94.8)$ & $19(5.2)$ \\
\hline July & $230(97.0)$ & $7(3.0)$ \\
\hline August & $281(94.0)$ & $18(6.0)$ \\
\hline September & $206(92.8)$ & $16(7.2)$ \\
\hline October & $18(100.0)$ & $0(0.0)$ \\
\hline Total & $2152(94.3)$ & $129(5.7)$ \\
\hline
\end{tabular}

${ }^{\mathrm{a}}$ Data are presented as No.(\%). 
As is shown in Table 1, there was an increase in the percentage of the parasite in February, June, August, and September. The distribution of the participating patients in terms of the provinces from which they came is given in Table 2 .

In this study, stool specimens obtained from 2281 patients with digestive system complaints were analyzed using saline preparation, acid-fast staining, and fluorescence microscopy, and Cyclospora spp. were found in 5.7\% of the feces samples. The distribution according to the complaints of the patients referring to the polyclinics is presented in Table 3.
Table 2. Provincial Distribution of the Patients Referring to the Polyclinic ${ }^{\text {a }}$

\begin{tabular}{|c|c|c|}
\hline Province & Negative & Positive \\
\hline Malatya/Center & $1868(94.4)$ & $111(5.6)$ \\
\hline Other provinces $\mathrm{b}$ & $124(96.1)$ & $5(3.9)$ \\
\hline Adiyaman & $79(91.9)$ & $7(8.1)$ \\
\hline Maraș & $81(93.1)$ & $6(6.9)$ \\
\hline Toplam & $2152(94.3)$ & $129(5.7)$ \\
\hline
\end{tabular}

Table 3. Distribution According to the Complaints due to the Parasite ${ }^{a}$

\begin{tabular}{lccc}
\hline Complaints/Disease & Negative & Positive & P Value \\
\hline Nausea/Vomiting & $91(4.2)$ & $9(7.0)$ & 0.139 \\
\hline Diarrhea & $688(32.0)$ & $46(35.7)$ & 0.384 \\
Constipation & $224(10.4)$ & $10(7.8)$ & 0.334 \\
Rectal Itching & $243(11.3)$ & $14(10.9)$ & 0.878 \\
\hline Weakness & $44(2.0)$ & $2(1.6)$ & 0.698 \\
Saliva & $365(17.0)$ & $23(17.9)$ & 0.799 \\
Abdominal Pain & $809(37.6)$ & $46(35.7)$ & 0.659 \\
Flatulence & $44(2.0)$ & $3(2.3)$ & 0.827 \\
Anorexia & $25(1.2)$ & $2(1.6)$ & 0.692 \\
Shortness of Breath & $22(1.0)$ & $2(1.6)$ & 0.568 \\
Joint Pain & $5(0.2)$ & $0(0.0)$ & 0.584 \\
Nocturia & $15(0.7)$ & $1(0.8)$ & 0.918 \\
Slimness & $49(2.3)$ & $2(1.6)$ & 0.588 \\
\hline Fever & $32(1.5)$ & $2(1.6)$ & 0.954 \\
\hline
\end{tabular}

${ }^{\mathrm{a}}$ Data are presented as No.(\%).

Our findings showed no association in the general assessment among the cases of general body itching, rectal itching, allergy, shortness of breath, diarrhea, abdominal pain, salivation, constipation, nausea, vomiting, and anemia $(P>0.05)$. However, the analysis of the positive cases revealed a significant difference $(\mathrm{P}<0.05)$.

\section{Discussion}

In the present study, we aimed to determine the epidemiology of Cyclospora spp. infection in Malatya province and its neighboring provinces. First the stool specimens of patients with digestive system complaints were analyzed and the findings were discussed and interpreted in terms of hypotheses. Cyclospora spp. infection is transmitted by the fecal-oral route, with the potential risk factors being the consumption of spring waters, polluted drinking water, and unwashed vegetables as well as contact with pets and contaminated soil. The incubation period is 1 to 11 days (9). Hassan-Rios (10) reported Cyclospora spp. infection in patients with gastroenteritis, diarrhea, ab- dominal pain, and vomiting. In Malatya province, where the present study was conducted, city water is used as drinking water. However, there has not been an investigation linking Cyclospora spp. infection to the water supply.

Diarrhea caused by C. cayetanensis is watery and without mucous and tends to be associated with malaise and continue for a day. Bloody diarrhea has also been reported. Diarrhea in patients whose immune system is well is likely to resolve within 3 to 4 days by itself, whereas in patients with suppressed immune system or AIDS as well as in individuals traveling to tropical countries it takes longer $(11,12)$. In our study population, with the chief complaint of diarrhea and abdominal pain, C. cayetanensis was detected in 35.7\% of the feces samples. Likewise, Cicek et al. (13) reported 2 diarrhea cases caused by C. cayetanensis. Tasbakan et al. (1) reported Cyclospora spp. as a gastroenteritis agent. Chopra (14) found the parasite in $1 \%$ of 200 patients with diarrhea in India. The disease control and prevention center (CDC) (15) reported 643 cases of Cyclospora spp. infection in 25 provinces of the USA in June-August 2013: 278 cases in Texas city (August), 153 in Iowa (June), and 86 in Nebraska (June). 
Karaman U et al.

In the present study, considering the monthly distribution of the positive cases, the incidence of the parasite showed a rise in the rainy season. Elsewhere, Lopez et al. (16) conducted a study between 2002 and 2011 and found the parasite in $12 \%$ of 167 cases in February and in $1.1 \%$ of 352 cases in April. The researchers reported that they found the parasite in February in 22.5\% of 71 children aged below 10 years, in April in 3.0\% of 135 children, and in January in $2.5 \%$ of 81 children and suggested that water sources might be a risk factor in contamination. In Haiti and its vicinity, infection was reported to be more prevalent between January and April, during the cool and dry months of the year (17), whereas in Nepal and Guatemala it was detected during the rainy seasons and in Peru in seasons with less rainfall (18). Turgay et al. (19) did not detect any parasites in İzmir during the months of December, January, and February; however, the infection appeared as sporadic cases in spring (i.e. March, April, and May) and started to escalate in the months of July and August. Similarly, we detected an increase in the percentage of Cyclospora spp. infection in Malatya province between February and June.

The first research on the presence of Cyclospora spp. was published as a case report $(1-4,6,7)$. The current study was performed primarily in Malatya province; nevertheless, other patients who were from the neighboring provinces were also recruited in the analysis. Our results demonstrated that the patients from Malatya province and its surrounding areas constituted $5.6 \%$ of the positive cases, while Cyclospora spp. were detected in $8.1 \%$ and $6.9 \%$ of the patients coming from Adryaman province and the Kahramanmaraş region, respectively. This finding indicates that a future epidemiologic study in these two regions may reveal a higher prevalence of Cyclospora spp. cases. Furthermore, 3.9\% of the positive cases were actually residing in another city but were in Malatya province on vacation.

The positivity rate (5.7\%) obtained in this study was restricted by the staining method. The relevant literature underscores the importance of the staining method in the routine diagnosis. Eberhard et al. (20) reported that Cyclospora spp. infection can be diagnosed by intensifying the multiplexed stool and painting it with special paints. Furthermore, thanks to the autofluorescence properties of oocysts, particular attention has been drawn to the role of fluorescence microscopy in providing a rapid, inexpensive, and sensitive technique for the diagnosis of Cyclospora spp. infection in stool samples (20). Indeed, one study reported that oocysts give bright, yellow-green fluorescent light in 380 - $420 \mathrm{~nm}$ excitation filters (3). Another efficacious diagnostic method with respect to Cyclospora spp. infection is acid-fast staining (8). In this regard, Vazquez Tsuji et al. (21) underlined the usefulness of the direct examination of fresh fecal matter with special acid-fast stains for a morphometric differentiation between Cyclospora spp. and other similar Coccidia parasites. Pape et al. (22) reported the use of acid-fast staining for the examination of stool samples for enteric protozoa.

In light of the findings of the present study, we suggest the following: 1) Given that our assessment of the epidemiology of $C$. cayetanensis was limited to Malatya province and its neighboring provinces, further investigations are required to include the other parts of the country, as well.

2) Experimental studies on the transmission of C. cayetanensis and ways and means to prevent it should be carried out.3) Considering the clinical signs in the diagnosis of $C$. cayetanensis, patients with long-term digestive system complaints should be directed to the laboratory so that the presence of the parasite can be investigated. 4) In cancer or immunosuppressed patients, in case of digestive system complaints, sampling should be done for the diagnosis of C. cayetanensis.

\section{References}

1. Tasbakan M, Yolasigmaz A, Pullukcu H, Sipahi OR, Yamazhan T, Turgay N, et al. [A rare gastroenteritis pathogen: Cyclospora]. Turkiye Parazitol Derg. 2010;34(2):95-7.

2. Turgay N, Yolasigmaz A, Uner A. [A human case of cyclosporiasis after traveling in the subtropics]. Turkiye Parazitol Derg. 2006;30(2):83-5.

3. Yazar S, Mistik S, Yaman O, Yildiz O, Ozcan H, Sahin I. [Three diarrheal cases caused by Cyclospora cayetanensis in Kayseri]. Turkiye Parazitol Derg. 2009;33(1):85-8.

4. Albert MJ, Kabir I, Azim T, Hossain A, Ansaruzzaman M, Unicomb L. Diarrhea associated with Cyclospora Sp. in Bangladesh. Diagn Microbiol Infect Dis. 1994;19(1):47-9.

5. Yazar S, Yaman O, Demirtas F, Yalcin S, Yucesoy M, Sahin I. Cyclospora cayetanensis associated with diarrhea in a patient with idiopathic compensated hepatic cirrhosis. Acta Gastroenterol Belg. 2002;65(4):241-4.

6. Kılbaș ZG, Yenicesu M, Araz E, Mehmet T. Renal Transplantlı Bir Hastada Cyclospora Cayetanensis Enfeksiyonu. Turkish Hyg Exp Biol. 2009;66(1):25-7.

7. Koc AN, Aygen B, Sahin I, Kayabas U. Cyclospora sp. Associated with Diarrhea in a Patient with AIDS in Turkey. Tr J Med Sci. 1998;28:577-8.

8. Centers for Disease Control and Prevention.. Cyclosporiasis (Cyclospora Infection). Diagnosis. USA: CDC; 2014. Available from: http://www.cdc.gov/parasites/cyclosporiasis/diagnosis.html.

9. Mansfield LS, Gajadhar AA. Cyclospora cayetanensis, a food- and waterborne coccidian parasite. Vet Parasitol. 2004;126(1-2):73-90.

10. Hassan-Rios E. Surveillance for waterborne disease outbreak, Puerto Rico, 2007-2011.: American Public Health Association; 2013. Available from: https://apha.confex.com/apha/141am/webprogramadapt/Paper287887.html

11. Ortega YR, Roxas CR, Gilman RH, Miller NJ, Cabrera L, Taquiri C, et al. Isolation of Cryptosporidium parvum and Cyclospora cayetanensis from vegetables collected in markets of an endemic region in Peru. Am J Trop Med Hyg. 1997;57(6):683-6.

12. Fleming CA, Caron D, Gunn JE, Barry MA. A foodborne outbreak of Cyclospora cayetanensis at a wedding: clinical features and risk factors for illness. Arch Intern Med.1998;158(10):1121-5.

13. Cicek M, Ucmak F, Ozekinci T. [Two diarrhea cases caused by Cyclospora cayetanensis]. Mikrobiyol Bul.2011;45(3):553-7.

14. Chopra RD, Dworkin MS. Descriptive epidemiology of enteric disease in Chennai, India. Epidemiol Infect. 2013;141(5):953-7.

15. Centers for Disease C, Prevention.. outbreaks of cyclosporiasis-United States, June-August 2013. MMWR Morb Mortal Wkly Rep. 2013;62(43):862.

16. Lopez AS, Bendik JM, Alliance JY, Roberts JM, da Silva AJ, Moura IN, et al. Epidemiology of Cyclospora cayetanensis and other 
intestinal parasites in a community in Haiti. J Clin Microbiol. 2003;41(5):2047-54.

17. Eberhard ML, Nace EK, Freeman AR, Streit TG, da Silva AJ, Lammie PJ. Cyclospora cayetanensis infections in Haiti: a common occurrence in the absence of watery diarrhea. Am J Trop Med Hyg. 1999;60(4):584-6.

18. Eberhard ML, Arrowood MJ. Cyclospora spp. Curr Opin Infect Dis. 2002;15(5):519-22.

19. Turgay N, Yolasigmaz A, Erdogan DD, Zeyrek FY, Uner A. Incidence of cyclosporiasis in patients with gastrointestinal symptoms in western Turkey. Med Sci Monit. 2007:13(1):CR34-9.

20. Eberhard ML, Pieniazek NJ, Arrowood MJ. Laboratory diagnosis of Cyclospora infections. Arch Pathol Lab Med.1997;121(8):792-7.

21. Vazquez Tsuji O, Jimenez Dominguez R, Campos Rivera T, Valencia Rojas S, Romero Cabello R, Gamez Aranda V, et al. [Cyclospora cayetanensis infection. Laboratory diagnosis]. Rev Latinoam Microbiol. 2000;42(1):45-52.

22. Pape JW, Verdier RI, Boncy M, Boncy J, Johnson WJ. Cyclospora infection in adults infected with HIV. Clinical manifestations, treatment, and prophylaxis. Ann Intern Med.1994;121(9):654-7. 